\title{
MAPEAMENTO SISTEMÁTICO DA LITERATURA CIENTÍFICA SOBRE EGRESSOS DE CURSOS TÉCNICOS E SUPERIORES DE INFORMÁTICA E EMPREGABILIDADE
}

\author{
MAPEO SISTEMÁTICO DE LA LITERATURA CIENTÍFICA EN CURSOS TÉCNICOS \\ Y SUPERIORES DE INFORMÁTICA Y EMPLEABILIDAD
}
SYSTEMATIC MAPPING OF SCIENTIFIC LITERATURE ON TECHNICAL AND SUPERIOR COMPUTING COURSES AND EMPLOYABILITY

RESUMO: Este artigo apresenta resultados de pesquisa do tipo mapeamento sistemático que objetivou apresentar o potencial de empregabilidade de egressos de cursos de informática, em nível técnico e graduação, e sua relação com o desenvolvimento local. Para isso, foram selecionadas 11 publicações científicas de 2011 a 2018 que tiveram como campo de pesquisa respostas de egressos de cursos técnicos ou superiores de Informática. A análise dos dados foi orientada pelo método Materialista Histórico-Dialético. Os resultados mostram que, em sentido lato, a empregabilidade dos profissionais da informática é alta; os egressos de cidades com maior malha industrial-tecnológica, em quase 100\%, conseguem bons empregos nessa área, mas, aqueles de cidades em situação oposta, quase na mesma proporção, atuam fora da área de formação ou estão desempregados. Assim, foi possível perceber que somente a formação técnica ou superior não garante emprego e desenvolvimento na e da localidade onde foi efetuada a formação, pois, este último depende, também, da existência de empresas da mesma área e de outros fatores sociais.

PALAVRAS-CHAVE: Egressos. Cursos de informática. Empregabilidade.

RESUMEN: Este artículo presenta resultados de búsqueda del tipo mapeo sistemático. El objetivo fue conocer la relación entre la calificación profesional y el potencial de empleabilidad de los egresados de informática de la región donde ocure la formación. Para esso, se seleccionaron 11 publicaciones cientificas de 2011 a 2018, cuyo campo de investigación incluyó respuestas de egresados de cursos de educación técnica o superior en Informática. El análisis de los datos fue guiado por el método materialista históricodialéctico. Los resultados muestran que, en un sentido amplio, la empleabilidad de los profesionales de la informática es alta; los egresados de ciudades con mayor entramado industrial-tecnológico, en casi el 100\%, consiguen buenos empleos en este ámbito, pero los de ciudades en situaciones opuestas, casi en la misma proporción, trabajan fuera del área de formación o están en paro. Así, se pudo constatar que solo la educación técnica o superior no garantiza el empleo y desarrollo en y del lugar donde se realizó la capacitación, ya que esta última también depende de la existencia de empresas en la misma área y otros factores sociales.

PALABRAS CLAVE: Graduados. Cursos de informática. Empleabilidad.

${ }^{1}$ Instituto Federal de Educação, Ciência e Tecnologia de Goiás (IFG), Inhumas - GO - Brasil. Professora Titular da área de Informática. Doutora em Educação (PUC Goiás). ORCID: https://orcid.org/0000-0002-2638-6314. Email: renata.costa@ifg.edu.br

RPGE- Revista on line de Política e Gestão Educacional, Araraquara, v. 25, n. 3, p. 2670-2693, set./dez. 2021. e-ISSN: 1519-9029 DOI: https://doi.org/10.22633/rpge.v25i3.14353 
ABSTRACT: This article presents results regarding systematic mapping research. The aim was to obtain knowledge about the relationship between professional qualification and employability potential of computer graduates in the region where the training is offered. To this end, 11 scientific publications from 2011 to 2018 were selected, whose research field included responses from graduates of technical or higher education courses in Informatics. Data analysis was guided by the Historical-Dialectic Materialist method. The results show that, in a broad sense, the employability of computer professionals is high; graduates from cities with a greater industrial-technological network, in almost 100\%, get good jobs in this area, but those from cities in opposite situations, almost in the same proportion, work outside the training area or are unemployed. Thus, it was possible to see that only technical or higher education does not guarantee employment and development in and in the location where the training was carried out, as the latter also depends on the existence of companies in the same area and on other social factors.

KEYWORDS: Graduates. Computer courses. Employability.

\section{Introdução}

A realidade vivida pelos egressos de um curso deve ser analisada, se realmente há preocupação em oferecer formações que colaborem com a transformação social dos sujeitos e de sua sociedade (MACHADO, 2001), pois, a sociedade é aquilo que os seus cidadãos são.

Quanto à formação dos cidadãos, as instituições de ensino superior e técnico exercem importante papel na sua formação profissional e geral, pois tratam do aprofundamento do desenvolvimento intelectual e do ensino de uma profissão aos estudantes de maneira muito próxima às possibilidades do mundo do trabalho, tendo em vista que, em sua maioria, lidam com indivíduos que estão caminhando para o final da adolescência ou já são adultos, como é o caso dos cursos superiores.

Embora haja consideráveis diferenças entre universidades e instituições especificamente de ensino em nível técnico, ambas precisam ocupar-se das relações que envolvem a qualidade do estudante formado, aqui referenciado por egresso, e sua empregabilidade. Estas questões são de grande relevância tanto para as instituições formadoras quanto para a sociedade em geral. Para a primeira porque sua razão de existência é a formação do indivíduo para a sociedade; para a sociedade em geral porque ela precisa do cidadão qualificado e formado para alimentar os processos de desenvolvimento social, econômico e político, em amplo sentido (BRUNO, 2011).

No que diz respeito aos postos de trabalho, especificamente da área de Informática, em diferentes níveis, dados de diferentes entidades, nacionais e internacionais, previram a falta de profissionais qualificados e algumas partes do mundo já vivenciam essa falta de profissional 
qualificado para as vagas ligadas às Tecnologias da Informação e Comunicação (TIC) (SOFTEX, 2012; 2013; 2019).

Quando averiguamos os caminhos traçados por egressos de um curso, podemos verificar se eles atuam e de que forma atuam no mundo trabalho, podendo também identificar características de sua situação pessoal e particular que influenciam na situação profissional. Por meio da atuação profissional, pós-conclusão de curso, também é possível captar as percepções do profisssional recém-formado no que diz respeito às suas dificuldades de inclusão no mercado profissional que busca.

Machado (2001, p. 45) explica que o acompanhamento de egressos é "um mecanismo que proporciona um quadro fiel do processo de inserção do ex-aluno no mundo do trabalho", o que significa dizer que, conhecer a trajetória profissional deles possibilita obter informações sobre a formação oferecida e a sociedade em que vivem e atuam o que, por sua vez, subsidia decisões mais acertadas sobre o que as instituições precisam rever em seus cursos.

Diante do exposto, a pergunta de pesquisa que orienta este artigo científico é: Como está a empregabilidade de egressos de cursos de informática, de nível técnico e de graduação, de instituições públicas, em relação ao desenvolvimento local e regional? Para isso, foi feito mapeamento sistemático sobre pesquisas voltadas para egressos de cursos de informática, de nível técnico e superior, publicadas de 2011 a 2018.

Desse modo, este artigo tem por objetivo apresentar um mapeamento sistemático sobre o potencial de empregabilidade de egressos de cursos de informática, em nível técnico e graduação, e sua relação com o desenvolvimento local.

\section{Relações entre educação e trabalho: egressos, formação crítica e empregabilidade}

As relações entre trabalho, educação e desenvolvimento são complexas porque envolvem a formação de pessoas ao longo da vida, objetivos sociais, nos quais se incluem aqueles de ordem econômico-social, e necessitam de investimentos por parte da sociedade.

Assumindo que vivemos numa sociedade capitalista, frequentemente, aspectos de ordem econômica são fortemente considerados de maneira isolada de outros componentes sociais para tomar decisões quanto à formação dos cidadãos. Todavia, o Brasil é um dos países que vive as perdas desse tipo de decisão, pois, uma vez que os ciclos formativos dos cidadãos não atendem nem a formação comportamental e nem a profissional dos indivíduos em níveis qualitativos, a inclusão desses indivíduos na sociedade, bem como sua atuação pessoal e profissional, podem pouco colaborar com a transformação do país: “O nível de 
desenvolvimento atingido pela sociedade contemporânea coloca a exigência de um acervo mínimo de conhecimentos sistemáticos, sem o que não se pode ser cidadão, isto é, não se pode participar ativamente da vida da sociedade" (SAVIANI, 2007, p. 160).

$\mathrm{Na}$ sociedade atual, a escola e outras instâncias de educação tornaram-se importantes agentes de formação da classe trabalhadora, tendo em vista as exigências de qualificação dos processos produtivos. Com o avanço da microeletrônica e, depois, do acesso à informação, levando à chamada Sociedade em Rede (CASTELLS, 2000), atualmente, o processo de formação dos trabalhadores tem sido cada vez mais exigente no que diz respeito aos requisitos necessários para se manter empregado, envolvendo aspectos intelectuais e comportamentais.

Em que pesem as questões de exploração do trabalho na sociedade do capitalismo tradicional que aqui não serão discutidas, o fato é que está na raiz dessa sociedade a busca pelo aumento da lucratividade. Com isso, continuamente, há a busca pelo desenvolvimento científico-tecnológico em função de criar mecanismos técnicos, tecnológicos e/ou metodológicos que transformem os processos produtivos em suas dimensões quantitativa e qualitativa para melhor, de maneira que possam ressignificar os ganhos. Por essas razões, o desenvolvimento econômico tem estreitos laços com os processos educacionais: "apenas o acréscimo das qualificações decorrente de uma formação mais complexa do trabalhador permite a introdução de inovações e garante que se trabalhe eficazmente com elas, viabilizando os ganhos de produtividade" (BRUNO, 2011, p. 549). Essa realidade desencadeia a constante demanda por qualificação e requalificação profissional, o que reforça a importância da escola e das instituições de ensino técnico e superior enquanto principais meios de formação dos cidadãos trabalhadores.

Cazarotti e Bernardes (2018), ao pesquisar as relações do ensino superior no Brasil com as possibilidades de ingresso dos estudantes no mercado, acrescentam que, embora seja importante manter a formação ligada com a realidade socioeconômica para preparação para o mercado de trabalho, deixar de abordar a formação crítica e social traz perdas também:

\footnotetext{
É importante observar que existe um evidente descompasso entre a universidade e a realidade social brasileira. De um lado, porque a universidade não tem assumido o seu papel de agente estratégico do desenvolvimento nacional. De outro, porque também não tem contribuído, em certa medida, para a crítica acerca dos modelos de desenvolvimento até hoje implementados de forma autoritária no país (CAZAROTTI; BERNARDES, 2018, p. 1026).
}

Nessa realidade, é relevante analisar a situação dos egressos, isto é, alunos que concluíram cursos de formação profissional em uma determinada instituição, a fim de 
verificar se tais formações têm contribuído para sua transformação social e, consequentemente, da sociedade em que vive, além de, a partir da verificação contraposta com a realidade do mundo de trabalho servir de subsídio para as decisões ligadas ao currículo de formação desses profissionais. Ao mesmo tempo em que não se pode ter um currículo restrito às necessidades do mercado de trabalho, também não é adequado oferecer formações que as neguem, pois é nesse mercado que os cidadãos vão atuar, o que coloca a exigência mínima de ter que atendê-lo. O cuidado deve ser rigoroso em não se ater a esse mínimo de habilidades e competências técnicas e tecnológicas, mas enriquecer o currículo com a formação científica e humanística necessária para o desenvolvimento crítico e criativo do cidadão:

Apenas os conhecimentos técnicos adquiridos quando da formação acadêmica não bastam para uma atuação eficaz nesse momento de economia globalizada e descentralizada da economia capitalista, além disso, são necessários um conjunto de habilidades e competências comportamentais (IEGER, 2014, p. 113).

Machado (1989, p. 117) acrescenta que “[...] a educação, embora possa contribuir para corrigir eventuais desequilíbrios no mercado de mão de obra, ela não pode por si só, alterar a estrutura ocupacional e tampouco a estrutura social, que é determinada pelas relações de produção".

A economista Mariana Mazzucato (2014) explica que é necessário que o Estado assuma suas já existentes e intensas intervenções no mercado, especialmente no que diz respeito às inovações tecnológicas, e invista, também, na criação de mercados. Para a autora em questão, segundo Santos (2017), quanto à inovação, a atuação do Estado propicia o engajamento do empresariado, ao criar condições de investimento. Nessa linha, Mazzucato (2014) evidencia o quanto são significantes os investimentos públicos em pesquisas para inovação e que esse é um importante caminho a ser trilhado por meio de parcerias públicoprivadas simbióticas, em busca do desenvolvimento sustentável motivado pela inovação, pois o Estado tem a premissa de diminuir riscos e criar incentivos dando condições para o desenvolvimento. Por sua vez, esse processo gera empregos que demandam qualificação e dá movimento à roda para o progresso.

À medida que a sociedade tem transformado seus modos produtivos, as demandas de formação dos trabalhadores vão mudando. Essa é uma das razões que justifica esse tipo de pesquisa com egressos: para verificar, quanto à empregabilidade, como tem sido a contribuição das formações oferecidas. Essa verificação torna-se ainda mais relevante quando 
a instituição provedora é da esfera pública, pois é imprescindível acompanhar os investimentos públicos e seu retorno para própria população.

Nesse sentido, Fernandes (2012) avalia a empregabilidade sob duas dimensões: lato, que se refere à empregabilidade em qualquer área; e estrito, a qual se refere à análise da empregabilidade com relação à área de formação. Para objetivos de transformação local e regional, é preciso verificar a empregabilidade estrita e analisar o papel da instituição educacional formadora dos profissionais dentro da totalidade social em que está inserida.

Pesquisar egressos de um curso, portanto, significa buscar compreensão da sua realidade em contraposição àquela encontrada para o exercício da cidadania e para o exercício profissional, proporcionando conhecimento para repensar as complexas relações entre educação e trabalho, e subsidiar decisões quanto às formações oferecidas à sociedade.

\section{Metodologia da pesquisa}

O Mapeamento Sistemático de Literatura (MSL), também conhecido por Estado da Arte, é essencial para garantir a credibilidade científica, a assunção de que os avanços científicos são um processo de continuação das atividades da comunidade científica e não a concorrência entre si e por si, e, ainda, serve à exploração do conhecimento existente na área pesquisada, a fim de melhor formular o problema de pesquisa, seus objetivos e, posteriormente, a metodologia a ser empregada.

Uma pesquisa de revisão sistemática de literatura tem como resultado um levantamento bibliográfico analisado de pesquisas concluídas sobre um tema delineado, visando identificar lacunas que precisem ainda de outras pesquisas para encontrar resultados mais refinados ou para trazer novo conhecimento sobre as relações entre as conclusões já encontradas daquele conjunto de pesquisas analisadas (DERMEVAL; COELHO; BITTENCOURT, 2020; HULLEY et al., 2015).

O mapeamento sistemático, aprofundado e rigoroso de um tema a ser pesquisado, é fase obrigatória que visa explorar o conhecimento científico já produzido naquela área, propiciar a produção de conhecimento inovador e, então, fundamentar a credibilidade da pesquisa científica e dos seus resultados.

Em busca de desenvolver procedimentos metodológicos com a cientificidade supramencionada, foi feito levantamento bibliográfico, seguido de sistematização e análise crítica do mesmo. 
Para realização do levantamento bibliográfico inicial, foi realizada busca no Google Acadêmico, no site da Revista Brasileira de Informática na Educação (RBIE) e nas bases do Congresso Brasileiro de Informática na Educação (CBIE), com os seguintes descritores compostos: egressos cursos informática, empregabilidade egressos cursos informática, situação profissional de egressos cursos informática, acompanhamento de egressos cursos informática e Congresso Brasileiro de Informática na Educação (CBIE) egressos informática, com período de delimitação de 2011 a 2019, a fim de recuperar pesquisas mais atualizadas. A RBIE e o CBIE são os principais veículos de comunicação científica da linha de pesquisa Informática na Educação no Brasil. Por essa razão, foram incluídos nas bases de dados para esta revisão sistemática.

Como critério de seleção, foram lidos os títulos e resumos de todas as pesquisas retornadas das 30 primeiras páginas do portal de busca, e selecionadas aquelas publicações que tinham a palavra "técnico", "técnico integrado", "EJA" ou "superior", de maneira associada com outra palavra que indicasse que a pesquisa fazia análise de egressos e não do perfil do egresso. Isto quer dizer que foram excluídas as pesquisas que tratavam apenas do perfil do egresso, ou seja, sem foco no aluno já formado.

Na RBIE, foram encontrados apenas quatro artigos que tratavam de egressos, sendo: dois de formação continuada para professores de áreas diversas; um a respeito de evasão em curso de Ciência da Computação; e um sobre análise curricular nessa mesma habilitação. Nenhum desses artigos foi selecionado devido não tratar de egressos de cursos de informática.

No Google Acadêmico, com o último descritor foram selecionadas três publicações de pesquisas. Do primeiro descritor, foram selecionadas cinco e do segundo descritor, apenas dois.

Publicado nos eventos do CBIE, foi encontrado um artigo sobre egressos de Licenciatura em Computação, publicado em 2013, o qual atendeu aos critérios de inclusão desse mapeamento.

Ao todo, foram, então, foram selecionados 11 textos científicos, conforme o Quadro 1 apresenta, para serem analisados nesta pesquisa.

Quadro 1 - Trabalhos científicos selecionados para a MSL sobre egressos de informática

\begin{tabular}{|c|c|c|}
\hline Título da pesquisa & $\begin{array}{c}\text { Instituição pesquisada/ano } \\
\text { de publicação }\end{array}$ & Nível/Curso pesquisado \\
\hline $\begin{array}{c}\text { Da qualificação ao mercado de } \\
\text { trabalho: um estudo de caso com } \\
\text { egressos de um curso superior de } \\
\text { informática no Paraná }\end{array}$ & $\begin{array}{c}\text { Universidade Federal do } \\
\text { Paraná (UFPR) - Curitiba }\end{array}$ & $\begin{array}{c}\text { Tecnológico em Análise e } \\
\text { Desenvolvimento de Sistemas }\end{array}$ \\
\hline
\end{tabular}


Empregabilidade dos egressos tecnólogos do curso de Análise e Desenvolvimento de Sistemas nos institutos federais mineiros

Educação tecnológica e empregabilidade: revelações de

$$
\text { egressos }
$$

Institutos Federais Mineiros de 3 cidades do interior mineiro: Bambuí, Januária e Uberaba (MG) - 2016.
Tecnológico em Análise e Desenvolvimento de Sistemas

Educação tecnológica e empregabilidade: revelações de egressos

Caminhos do Licenciado em Computação no Brasil: Estudo de Mercado a Partir de uma Pesquisa com Egressos

Empregabilidade dos egressos: a educação profissional integrada ao ensino médio no extremo norte da Amazônia.

O papel do instituto federal de educação, ciência e tecnologia

(IFRN) para a qualificação e empregabilidade: um estudo dos egressos do curso de informática do IFRN em Currais Novos/RN Itinerários dos egressos do nível médio integrado do IFBA -

$$
\text { Câmpus Jacobina }
$$

Programa de mapeamento de egressos relatório 2015-2016

O acompanhamento de egressos como ferramenta de inserção no mercado de trabalho.

Em busca do "tesouro": inserção profissional e inclusão digital nas trajetórias de

egressos/integralizados de um curso de técnico em informática ProEJA

Fonte: Elaborado pela autora a partir dos dados da pesquisa

Instituto Federal Sul Rio Grandense (IFSUL) Charqueadas(SC) - 2011 .
Tecnológico em Análise e Desenvolvimento de Sistemas

(IFGoiano) - Urutaí (GO) 2012.

Universidade de Brasília

(UNB) - Brasília (DF) 2017.

Licenciatura em Computação

Universidade Estadual da

Paraíba - Campus I -

Campina Grande (PB) 2013.

Instituto Federal de Roraima

(IFRR) - Câmpus Boa Vista (RR) - 2018 .

Instituto Federal do Rio

Grande do Norte (IFRN) -

câmpus Currais Novos (RN) $-2011$.

Licenciatura em Computação

Cursos técnicos integrados ao ensino médio em Secretariado,

Eletrônica, Eletrotécnica e Informática.

Instituto Federal da Bahia (IFBA) câmpus Jacobina -

Técnico integrado em Mineração, Jacobina (BA) - 2018.

Técnico subsequente ao Ensino Médio em Informática

Instituto Federal Catarinense

- Câmpus Videira - Videira (SC) - 2017.

CEFET Rio de Janeiro -

Unidade Maracanã (RJ) 2014.

Eletromecânica e Informática

Egressos de 2015-2016

Egressos de 2012

Técnico em Informática integrado ao Ensino Médio na modalidade de Educação de Jovens e Adultos

Conforme pode ser observado no Quadro 1, dos 11 textos selecionados, cinco referemse à nível superior, sendo três tecnológicos em Análise e Desenvolvimento de Sistemas e dois de Licenciatura em Computação. Dentre os outros seis textos, dois analisam egressos por ano, sem separação por nível, três tratam de egressos de cursos técnicos integrados ao Ensino Médio e um aborda o caso de egressos de curso técnico integrado formados pelo sistema de Educação de Jovens e Adultos (EJA).

Apesar de não ter sido colocada como critério, a esfera pública como campo de investigação está presente em todas as pesquisas aqui selecionadas, sendo os cursos e egressos participantes formados em centros federais de educação tecnológica, institutos federais e 
universidades estaduais e federais. Embora haja diferenças entre objetivos de instituições universitárias e de institutos e centros federais de educação técnica e tecnológica, para este mapeamento, o foco não está na diferenciação entre essas instituições, mas sim na verificação de aproximações de empregabilidade de egressos de cursos de informática, independentemente de serem de cursos técnicos ou superiores. Além disso, em que pese a maior acentuação dos institutos federais na formação técnica, sua orientação políticofilosófica difere das instituições de rápida formação profissional, sendo tais institutos defensores da formação completa dos trabalhadores (COSTA; LIBÂNEO, 2018), ou seja, humana e científico-tecnológica, o que indica similaridades com instituições universitárias.

A análise de dados foi orientada pelo método Materialista Histórico-Dialético (MHD), isto é, foram exploradas, nos textos, as relações entre cada caso particular e em relação à totalidade inserida, bem como se buscou evidenciar as contradições e mediações que caracterizam o objeto observado: as relações entre qualificação oferecida, potencial de empregabilidade e local da instituição. Assim, esses três aspectos constituem as categorias empíricas exploradas nesta pesquisa de maneira orientada pelas características constitutivas do método MHD (COSTA; SOUZA; THEREZA JUNIOR, 2020).

\section{Formação técnica e superior em informática e potencial de empregabilidade}

Das cinco pesquisas encontradas realizadas com egressos de cursos de informática em nível técnico, quatro trataram com egressos de institutos federais e um com um Centro Federal de Educação Tecnológica (CEFET).

A pesquisa realizada com egressos do Instituto Federal de Roraima (IFRR) (CARDOSO, 2018) teve como campo depoimento de 20 egressos de cursos técnicos integrados ao Ensino Médio do câmpus Boa Vista, formado de 2014 a 2016. Esse campus se localiza na cidade de Boa Vista, capital do Estado de Roraima, e possui, aproximadamente, 500.000 habitantes (CARDOSO, 2018).

Cardoso (2018, p. 172) conclui que o mercado local não oferece ocupações para aqueles formados nas áreas de Secretariado, Eletrônica, Eletrotécnica e Informática, ressaltando a constatação de que " $90 \%$ desses egressos não trabalha, nem atua na área de sua formação técnica". Por outro lado, destaca que dentre esses $90 \%$ desviados da área de formação técnica, $41 \%$ segue estudando curso superior na Universidade Federal de Roraima, em áreas diversas. 
Também foi constatado, nessa pesquisa, que "a maioria dos egressos estava satisfeita com os conhecimentos adquiridos na instituição, apesar do desemprego recorrente e das ocupações precárias em áreas diversas da formação" (CARDOSO, 2018, p. 170). Se por um lado há satisfação pessoal com as aprendizagens adquiridas, por outro, da parte do mercado, não há o equivalente. Sobre isso, o autor segue afirmando, ainda, que a "instituição poderia discutir essa situação de não inserção do egresso com as comunidades interna e externa, a fim de apresentar alternativas a este processo". Esse posicionamento faz enlace com a defesa de Mazzucato (2014) acerca da necessária intervenção do poder público para a criação de mercados que empregue, de fato, os locais, pois só oferecer a formação é in suficiente para sua permanência e desenvolvimento na região.

A pesquisa realizada no campus Currais Novos do Instituto Federal do Rio Grande do Norte, foi desenvolvida por meio de questionários aplicados a 57 egressos do Curso Técnico de Nível Subsequente de Informática, formandos de 2008 a 2010 (VIEIRA; GOMES; SILVA, 2011). O município de Currais Novos localiza-se a 172 quilômetros da capital Natal e possui, aproximadamente, 50.000 habitantes.

Vieira, Gomes e Silva (2011) compararam a situação do egresso à época da pesquisa com sua situação anterior a tal formação. Eles concluíram que os $10 \%$ que possuíam trabalho formal antes do curso havia subido para $62 \%$ e os $42 \%$ de desempregados, agora, representavam 10\%. Além disso, 75\% dos participantes destacaram que seu trabalho atual era na área da informática. Nesse sentido, pode-se dizer que, para o período pesquisado, houve empregabilidade estrita à área de formação dos egressos (FERNANDES, 2012), o que endossa a importância do curso em questão para a sociedade regional em questão no que diz respeito à demanda de mão de obra existente.

Outra importante constatação sobre os egressos de Currais Novos foi de que $90 \%$ dos egressos pesquisados afirmaram estar satisfeitos quanto às expectativas dos conhecimentos adquiridos na área de informática (VIEIRA; GOMES; SILVA, 2011).

No campus Jacobina do Instituto Federal da Bahia (IFBA), foi realizada pesquisa com egressos do ano de 2016 dos cursos técnicos integrados em Mineração, Eletromecânica e Informática (SANTOS et al., 2018). Foi enviado questionário on-line a 77 egressos, sendo que $66 \%$ enviaram suas respostas ao pesquisador. A cidade de Jacobina localiza-se no extremo norte da Bahia, a 339 quilômetros da capital Salvador e sua população é de pouco mais de 80.000 habitantes.

Dos egressos pesquisados, durante os estudos no IFBA campus Jacobina, $70 \%$ residiam nessa mesma cidade e $30 \%$ cidades vizinhas. Também foi verificado que $72 \%$ dos 
entrevistados continuam seus estudos em nível superior, ainda que apenas $12 \%$ estejam atuando na mesma área da formação técnica. Santos et al. (2018) inferem, então, que apesar da formação técnica contribuir para a empregabilidade, esta ocorre em sentido lato (FERNANDES, 2012), não sendo possível confirmar a relação da formação com atendimento das necessidades de mão de obra da região e nem o seu contrário.

Nesse sentido, os autores concluem que a formação técnica recebida tem contribuído mais com a formação geral integrada, servindo à qualificação formativa para alcançar o nível superior. Isso pode ser corroborado pelo grau de satisfação informado pelos participantes da pesquisa que, em média, fica acima de $65 \%$ (contando aqueles que marcaram de média em diante): Eletromecânica, Informática e Mineração com satisfação Alta em 66,7\%, 52,6\% e 47,4\%, respectivamente (SANTOS et al., 2018).

Santos et al. (2018) constataram que há baixa empregabilidade para as áreas técnicas pesquisadas e que um dos aspectos que pode explicar isso é a fraca articulação de parcerias para a vinculação do jovem ao primeiro emprego: "Tais iniciativas precisam ser encampadas em parcerias entre os Institutos Federais, os arranjos produtivos locais e os demais agentes públicos e privados.” (SANTOS et al., 2018, p. 78). Nessa perspectiva, aparece, novamente, a necessidade da intervenção pública estatal a fim de articular e criar mercados nas regiões periféricas dos grandes centros, conforme recomenda Mazzucato (2014).

A respeito da pesquisa realizada pelo Instituto Federal Catarinense (IFCatarinense) campus Videira, é preciso esclarecer que a pesquisa integra um programa institucional de mapeamento dos egressos do campus. Isto quer dizer que os resultados são, na maioria, gerais, sem afunilar para a situação dos egressos da área de Informática e sem separação por nível de ensino. Nesse relatório em questão, a pesquisa envolveu egressos de cursos técnicos e de pós-graduação lato sensu oferecidos pelo campus Videira, e que ingressaram na instituição nos anos de 2010 a 2013 (ROSTIROLA; OLIVEIRA, 2017). O campus Videira localiza-se na cidade de mesmo nome, a 415 quilômetros da capital Florianópolis e possui população de, aproximadamente, 53.000 habitantes.

Dos 405 egressos convidados a responderem a pesquisa, $34 \%$ aceitou participar, sendo mais de $40 \%$ egressos dos cursos técnicos. Da amostra total, 55\% afirmou estar trabalhando na área, totalmente ou parcialmente (ROSTIROLA; OLIVEIRA, 2017). Além disso, 81\% se declararam satisfeitos com suas atividades profissionais e mais da metade (59\%) afirmou que trabalham na cidade do campus onde estudaram. Desse modo, as autoras concluem que o IFCatarinense campus Videira oferece cursos em consonância com a demanda regional e com os objetivos dos institutos federais. Por outro lado, fica evidenciado que dos $55 \%$ que 
trabalham na área da formação, apenas 38\% afirmaram ser totalmente na tal área, o que possibilita inferir que foi tratada a empregabilidade em amplo sentido. Nessa linha, pode haver questionamento sobre a relação entre formação oferecida e empregabilidade local (FERNANDES, 2012).

Outra importante verificação foi que mais de $63 \%$ dos egressos de nível técnico seguiu para um curso superior, o que levou Rostirola e Oliveira (2017) a confirmarem, também, a contribuição da formação para ascendência acadêmica. Similar ao caso de Currais Novos, apesar de ambas estarem distantes de suas capitais, os egressos do campus Videira apresentaram uma boa integração no mercado e ascensão escolar.

Quanto à pesquisa realizada pelo Centro Federal de Educação Tecnológica do Rio de Janeiro (CEFET-RJ), realizada com egressos do ano de 2012 dos cursos da Unidade Maracanã, sem separação por nível de ensino. Foram convidados, via e-mail, 524 egressos. A amostra total da pesquisa foi de 342 respondentes que aceitaram tal convite, configurando $65,27 \%$ do total de formados (GUIMARÃES; SALLES, 2014).

Guimarães e Salles (2014) perceberam que dos 57,6\% de egressos que estavam trabalhando, $52 \%$ era em sua área de formação, sendo que 54\% trabalham com carteira assinada. Além disso, mais de $83 \%$ afirmaram estar satisfeitos ou muito satisfeitos com a área de formação e $75 \%$ destacou que se interessaria em fazer outros cursos na escola, especialmente se houvesse processo seletivo exclusivo para ex-alunos.

Um aspecto importante que apareceu na pesquisa de Guimarães e Salles (2014), devido ter em seu campo de pesquisa as empresas da região, foi o fato dessas declarem que têm interesse em acessar um banco de dados institucional da escola em questão para analisar perfis em função de possíveis contratações, uma vez que analisam os egressos contratados e consideram a formação recebida no CEFET-RJ como excelente.

Quanto à pesquisa realizada com egressos de curso Técnico em Informática pelo Programa de Educação de Jovens e Adultos (PROEJA) do Instituto Federal Sul-RioGrandense (IFSULRS), campus Charqueadas, foi pesquisa de ordem qualitativa (NUNES, 2011). Charqueadas é uma cidade que faz parte da mesorregião metropolitana de Porto Alegre, situada a 60 quilômetro desta capital, e possui, aproximadamente, 38.000 habitantes.

Nunes (2011) percebeu que 73\% dos egressos trabalham, entretanto a maioria é fora da área da formação técnica. Os egressos entrevistados nesta pesquisa relataram que "entendem que apesar de existir demanda de serviço, existem poucas oportunidades de trabalho, principalmente na formalidade" (NUNES, 2011, p. 109). Eles esclarecem que muitas 
empresas terceirizam suas demandas de manutenção em hardware e software para outras empresas da região.

Nunes (2011) também entrevistou gestores do campus Charqueadas e o coordenador do curso, os quais corroboraram os depoimentos dos egressos explicando que essa falta de postos de trabalho formais na cidade foi, inclusive, um dos motivos do encerramento do curso. Esses gestores informam que as poucas demandas de trabalho na área de Informática referem-se a atividades de prestação de serviços independentes, isto é, como autônomos. Nesse sentido, emergiu das falas que a divulgação do trabalho como autônomo, via redes sociais, influenciou muito a inserção no mercado de trabalho na área da Informática.

Infere-se da realidade supracitada que é necessária a intervenção do poder público para a criação de mercados, conforme assevera Mazzucato (2014), e é preciso rever os cursos que vêm sendo ofertados e onde, pois, retomando Cazarotti e Bernardes (2018, p. 1026), a "universidade brasileira precisa ficar atenta para não se situar à margem dos processos sociais, políticos e econômicos, voltada apenas aos seus objetivos internos, alheia às necessidades e reclamos da população". A conjugação dessas duas ações pode levar ao desenvolvimento local, promovendo a desaglomeração dos grandes centros.

A percepção de que há poucos postos formais de trabalho precisa ser avaliada sob vários aspectos, estando dentre eles, no mínimo, a atuação do poder público local articulada com o regional para criação de mercados que envolvam e distribuição de centros tecnológicos do Estado, por exemplo. Porto Alegre é uma das cidades brasileiras que mais concentra empresas do ramo da tecnologia digital (JORNAL DO COMÉRCIO, 2020). Isso mostra que a intensa ação pública local, cria mercados. Por outro lado, se não houver intervenção de poder público mais amplo, essa concentração local impede o desenvolvimento distribuído. Por exemplo, quais as condições de transporte público rápido há para os formados na área da Informática irem trabalhar na capital? Ou, então, por que não se cria esses mercados também fora das capitais? Essas questões impedem o tão falado desenvolvimento local e regional, mantendo-o nos grandes centros. Nesse sentido, pouco colabora com a formação de pessoas nos interiores do país, pois nesses lugares não têm sido criados mercados que geram empregos. Conforme explica Mazzucato (2014, p. 48-51), em vez disso, é necessário um

Estado direcionado, proativo, 'empreendedor', capaz de assumir riscos e criar um sistema altamente articulado que aproveita o melhor do setor privado nacional em um horizonte de médio e longo prazo. É o Estado agindo como principal investidor e catalisador, que desperta toda a rede para a ação e difusão do conhecimento. O Estado pode e age como criador, não como mero facilitador da economia do conhecimento. [...] O Estado está por 
trás da maioria das revoluções tecnológicas e longos períodos de crescimento. É por isso que um 'Estado-empreendedor' é necessário para assumir o risco e a criação de uma nova visão.

Santos (2015, p. 7), baseado em Mazzucato (2014), acrescenta:

A transição na infraestrutura tecnológica, entretanto, implica em enormes custos. O mercado não irá realizá-lo por sua própria conta, o que torna imprescindível um papel ativo do Estado. [...] O setor privado só se envolverá efetivamente após os níveis de risco e incerteza serem suprimidos ou, pelo menos, significativamente minimizados, de modo que os investimentos privados tenham um cenário mais estável para o retorno dos investimentos. A liderança do Estado se expressa por meio de políticas e investimentos públicos direcionados a formação dos conhecimentos, das oportunidades e estabilidade requeridas pelos atores que atuam no campo econômico.

Desse modo, o "Estado precisa também comandar o processo de desenvolvimento industrial, criando estratégias para o avanço tecnológico em áreas prioritárias" (MAZZUCATO, 2014, p. 71).

Um importante aspecto ressaltado por aqueles que conseguiram emprego formal na área da formação foi tal contratação ter ocorrido em decorrência do período de estágio durante o curso. Assim, a falta de estágio em ambiente empresarial, não só afeta a formação, mas a inserção do profissional na área de formação, alimentando as oportunidades informais e sem vínculo empregatício.

Quanto à predominância de oportunidades de trabalho sem vínculo empregatício, é preciso refletir, novamente, com relação à totalidade das ações públicas com vistas à transformação social. Se por um lado existe uma demanda considerada baixa, isto é, somente para atender o que já existe no mercado é possível que precise ser repensada, uma vez que as instituições públicas educacionais, especialmente os institutos federais, possuem, em seus objetivos, forte apelo para o desenvolvimento local e regional.

Nunes (2011) traz à tona uma antiga e, ao mesmo tempo, contemporânea questão: a área da Informática, no Brasil, não se destina apenas aqueles diplomados ou certificados para tal. Há profissionais que atuam baseados em suas experiências e em estudos autodidatas, o que "complexifica ainda mais o universo que caracteriza o mercado de trabalho para este profissional" (NUNES, 2011, p. 116).

Diante dessa realidade, conjugada a pouca oferta formal e maior atuação como profissional autônomo, torna-se relevante incluir na formação dos profissionais da informática conteúdos ligados ao empreendedorismo para micro e pequenos empresários. 
A pesquisa de Fernandes (2012), realizada com 61 egressos do curso Tecnológico em Análise e Desenvolvimento de Sistemas do Instituto Federal Goiano, câmpus Urutaí, corrobora os questionamentos de Nunes (2011) a respeito do potencial de empregabilidade com o desenvolvimento local e regional. Urutaí possui pouco mais de 3.000 habitantes e localiza-se a 170 quilômetros da capital do Estado, Goiânia. Situa-se entre Ipameri e Pires do Rio, que possuem 27.000 e 31.000 habitantes, respectivamente.

Dos 61 egressos participantes da pesquisa de Fernandes (2012), 50,82\% informou que trabalha em município com distância de até $50 \mathrm{~km}$ de Urutaí, o que pode ser representado na sua maioria pelos municípios de Ipameri e Pires do Rio, que são as duas cidades maiores dentro desse raio e totalizam $69,23 \%$ dos locais de residência de tais participantes.

Essa constatação, por um lado, pode indicar a atuação estratégica da instituição quanto ao seu papel de oferecer cursos de qualificação profissional na região e, por conseguinte, contribuir com a fixação dos egressos na área. De modo geral, verificou-se alto índice de empregabilidade dos egressos formados na escola em questão, aproximadamente, 93,84\%. Entretanto, foi verificado, também, que apenas $29,51 \%$ exercem atividades intrínsecas à sua área formação tecnológica. Para Fernandes (2012, p. 191), estes resultados permitem "questionar o alcance da proposta de empregabilidade, presente nos discursos pedagógicos, políticas públicas e o mundo do trabalho".

Ademais, é relevante registrar que $38,89 \%$ dos sujeitos pesquisados informaram residir em outro Estado ou País, sendo aqueles que seguiram carreira na área da formação e apresentaram os maiores salários (FERNANDES, 2012). Sendo assim, "é preciso relativizar os discursos sobre a oferta/demanda de qualificação x empregabilidade nesta área" (FERNANDES, 2012, p. 188), pois os índices de empregabilidade são menores quando cruzados os dados do município onde o curso é oferecido com as informações de onde a maioria dos egressos conseguiu seguir carreira e fixa residência.

A respeito das pesquisas realizadas com egressos de nível superior, a investigação de Alkmin e Heijmens (2016) com egressos do curso tecnológico em Análise e Desenvolvimento de Sistemas (ADS) foi realizada em três campus diferentes do interior de Minas Gerais: Bambui, Uberaba e Januária. Foram entrevistados, ao todo, 311 egressos formados entre 2006 e 2013.

Alkmim e Heijmens (2016) perceberam que quase $81 \%$ dos egressos dos três campus exercem suas atividades profissionais na área de informática. Importante ressaltar que "a maioria dos egressos não migrou para outros estados após a conclusão da graduação tecnológica, ou seja, 88,71\% exercem suas atividades profissionais em Minas Gerais" 
(ALKMIM; HEIJMENS, 2016, p. 2100). Mais de 50\% dos egressos de cada câmpus está empregado na sua mesorregião, com destaque para o campus Uberaba que reteve todos os entrevistados. Assim, mais da metade endossa a satisfação com o curso.

Bambuí foi o campus com menor retenção, próximo a 50\%. Trata-se de um município com, aproximadamente, 23.000 habitantes e economia agropecuária, principalmente, ligada à produção mineral, produção de milho, café, soja, cana de açúcar, usina de álcool e açúcar, produção de leite e carne (PREFEITURA DE BAMBUÍ, 2020).

O campus Januária localiza-se no norte de Minas Gerais, há, aproximadamente, 580 quilômetros da capital Belo Horizonte. A cidade de Januária possui em torno de 70.000 habitantes e economia baseada na agropecuária com forte produção de cana de açúcar e derivados. Possui centros comerciais e setor de serviços bem desenvolvidos, além de investimentos turísticos e atividades econômicas ligadas às mineradoras de Minas Gerais (FRANÇA; SOARES, 2011). Além disso, é considera cidade universitária com instituições públicas e privadas com buscam estabelecer relações parceiras para pesquisa e desenvolvimento, principalmente, em áreas ligadas aquelas às atividades do município. Essas características indicam que, apesar de pequena população, o município possui movimento econômico político e relações com instituições educacionais universitárias que alimentam sua microrregião, sendo esses aspectos uma das explicações para a retenção dos seus egressos em informática em pouco mais de $62 \%$.

O campus Uberaba apresentou o menor índice de desemprego em sua mesorregião e a maior média salarial para o nível superior. Isso pode ser explicado por localizar-se no Triângulo Mineiro, região com muitas indústrias, agropecuária e usinas que empregam tecnologias de alto nível e se preocupam com implementações sustentáveis (BRASIL, 2019). Além disso, Uberaba foi considerada a $2^{\text {a }}$ cidade mais inteligente e conectada de Minas Gerais e a $6^{\mathrm{a}}$ mais eficiente em geração de startups (ABSSTARTUP, 2018). A análise particular do município em relação à sua totalidade econômica e social precisa ser aprofundada, mas esses dados básicos mostram que há relação forte entre empregabilidade e investimento em tecnologias, conforme explica Mazzucato (2014), quando aborda o desenvolvimento econômico puxado pelos investimentos em tecnologia e inovação para geração de empregos e renda.

A pesquisa desenvolvida por Ieger (2014) coletou informações de 66 egressos de curso tecnológico em ADS da Universidade Federal do Paraná, formados entre 2004 e 2013, em Curitiba. Mais de $75 \%$ consideraram sua formação superior muito importante para estar empregado no posto atual, afirmando sua satisfação. Em torno de $25 \%$ já trabalhava na área 
antes do curso superior e $50 \%$ foi contratado durante o estágio. Por meio dessa pesquisa percebeu-se, também, que prevalecem, 92\%, os empregos em empresas de pequeno e médio porte com contratos de Pessoa Jurídica e outros tipos de trabalho autônomo.

A alta empregabilidade da região de Curitiba para a área de Informática pode ser explicada pela existência de um parque tecnológico que àquela época, 2014, possuía 24 empresas no parque de Software (IEGER, 2014), corroborando, mais uma vez, a tese de Mazzucato (2014), pois a região investe na criação de mercado de inovação e tem produzido empregabilidade na área de formação, o que endossa, também, o papel da instituição promotora da formação (FERNANDES, 2012).

Apesar do alto potencial de empregabilidade percebido na região de Curitiba, a predominância de contratação por diferentes tipos de contratos de serviços autônomos nas pequenas e médias empresas chamou a atenção da pesquisadora Ieger (2014) devido não ser considerado um trabalho formal quanto a direitos trabalhistas. Todavia, a pesquisadora explica que isso pode ser reflexo da alta necessidade de profissionais qualificados que são difíceis de serem encontrados na área da Informática (SOFTEX, 2013), o que, por outro lado, eleva os valores de contratação; ou, ainda, pode ser porque as grandes empresas contratam melhor os profissionais mais especializados (IEGER, 2014).

Quanto às pesquisas realizadas com egressos de cursos de Licenciatura em Computação, aquela realizada com egressos da Universidade de Brasília (UNB) (PINHEIRO, 2017) percebe alta empregabilidade, mas, por outro lado, oportunidades que não são ligadas à docência. O Distrito Federal possui grandes empresas, na área da Informática e em outras áreas, mas que, de toda forma, possuem departamentos consolidados na referida área, o que explica a empregabilidade de todos os egressos em empresas do ramo. Os salários acima da média de 4.000,00 reais, juntamente, com o sentimento de segurança em relação ao emprego, levam os participantes a reafirmarem sua satisfação com a formação. Entretanto, aqueles que gostariam de atuar também na docência destacam que é imprescindível o avanço de políticas públicas em incentivo à Licenciatura em Computação.

Os participantes da pesquisa de Pinheiro (2017) reforçam os depoimentos da realidade curitibana dizendo que em suas empresas, regularmente, há vagas abertas para área de informática que não são preenchidas com facilidade, lembrando que 50\% deles foram contratados logo ao final do estágio.

Luciano e Santos (2013) pesquisaram egressos de Licenciatura em Computação da Universidade Estadual da Paraíba, campus Campina Grande. Esta cidade possui, aproximadamente, 410.000 habitantes e situa-se a 133 quilômetros da capital do Estado, João 
Pessoa. Foram convidados, via e-mail, os 74 egressos do curso até 2012 . Houve retorno de 47 deles, o que representou uma amostra de $64 \%$ dos convidados.

Os dados revelaram que apenas $3 \%$ dos egressos não atuam em alguma área relacionada à tecnologia ou educação sendo Informática na Educação, Jogos Educacionais e Educação a Distância, os campos de trabalho mais citados com 23\%, 17\% e 16\%, respectivamente. Além disso, foi possível perceber que nenhum dos participantes estava desempregado, $28 \%$ com rendimentos acima de quatro salários mínimos e $73 \%$ afirmou estar satisfeito ou muito satisfeito com o trabalho (LUCIANO; SANTOS, 2013). Diferentemente do caso da UNB, observou-se alta empregabilidade na área da Licenciatura em Computação na região de Campina Grande.

\section{Considerações finais}

O mapeamento das pesquisas realizadas com egressos de cursos de Informática aqui relatadas foram analisadas e discutidas sob critérios científicos e, a partir disso, foi possível perceber algumas características quanto às relações entre a empregabilidade de tal egresso e a região onde é oferecido:

- $\quad$ Nas cidades menores que 70.000 habitantes, as oportunidades de trabalho são mais ligadas à assistência técnica de computadores e, em alguns casos, implantação e manutenção de redes de computadores de pequeno porte;

- Os empregos relacionados às áreas de desenvolvimento de software, aqueles ligados à indústria de software responsável pela produção de novos produtos e seus serviços agregados, estão, em maioria, nos grandes centros econômicos, ou seja, nas capitais ou cidades com alto índice de movimentação econômica de empresas de médio porte em diante;

- As cidades localizadas mais no interior dos Estados, quando há investimentos em malha industrial e desenvolvimento tecnológico, mesmo sendo pequenas, apresentam mais e melhores oportunidades de trabalho;

- $\quad$ O estágio é, em mais de $50 \%$ dos casos, a principal porta de contratação para o primeiro emprego.

Confrontando as tendências com os objetivos das instituições de ensino de contribuição ao fortalecimento do desenvolvimento regional, especialmente quando se trata de instituto federal, oferecer cursos focados na formação técnica em redes e assistência de 
computadores, em parte, atende ao mercado local das cidades de interior. Por outro lado, pouco colabora com a ampliação regional das atividades econômicas, pois não geram novos produtos e serviços. Além disso, a prestação de serviços de manutenção tem sido por meio de serviços autônomos.

A maior parte das empresas, nas regiões pouco industrializadas e interessadas em pesquisa e desenvolvimento regional, é de micro e pequena empresa e, nessa categoria, há poucas oportunidades de trabalho e, menos ainda, com registros formais. Assim, o desvio da área de formação é maior para aqueles que permanecem na cidade de formação, quando esta é pequena e com baixo índice de investimento tecnológico e industrial.

Fica evidente que somente a oferta de formação não gera riqueza nem transformação local significativa, embora contribua para a qualificação profissional da mão de obra local. Contraditoriamente, isso traz uma desvantagem aos egressos de cidades menores pouco industrializadas: com a alta quantidade de pessoas qualificadas e poucas oportunidades de trabalho, os salários se mantêm baixos, favorecendo as empresas que contratam um funcionário melhor qualificado por valores menores (IEGER, 2014).

A formação oferecida nas instituições dos interiores é de qualidade, pois aqueles que quiseram aprofundar na carreira migraram para capitais ou outras regiões com centros tecnológicos e estão empregados. Assim, do ponto de vista da formação, as instituições educacionais pesquisadas cumprem ensino gratuito e de qualidade, mas sua ação isolada do poder público local e regional diminui muito o potencial transformador, pois, ou o egresso vai migrar ou apenas alimentar o sistema existente. Do ponto de vista da instituição educacional, apresenta-se um dilema: Oferecer formação apenas conforme demanda existente? E a geração de desenvolvimento e riqueza local?

Observaram-se, também, mesmo nos locais indicados como baixa empregabilidade, que os egressos são satisfeitos com a formação que receberam durante o curso técnico ou superior. Quanto à transformação pessoal, destacam vários pontos como o enriquecimento cultural e habilidades interpessoais, que reconhecem ser diferencial para o emprego que conquistaram.

Se, dentre os objetivos da instituição educacional, houver a intenção de contribuir com o desenvolvimento local e regional de maneira transformadora, inclusive para tentar reter os egressos nas regiões interioranas, são imprescindíveis outras formas de investimento, por exemplo, investimento em pesquisa e inovação mesmo nos pequenos negócios, parcerias público-privadas e efetiva atuação estatal e municipal quanto à criação e atração de indústrias 
que vise, constantemente, o desenvolvimento tecnológico sustentável, para fora das capitais, o que significa formar minicentros tecnológicos espalhados pelos Estados.

A respeito das parcerias público-privadas, o que acontece são altos investimentos públicos para criação de mercados em vínculo com pesquisa e inovação, mas com pouca ou nenhuma exigência de contrapartidas das empresas privadas. Falta, da parte dos dirigentes públicos, pensar melhor a distribuição, geográfica e categórica, desses investimentos e do cumprimento de contrapartidas, por parte das empresas privadas, para as regiões que cedem os subsídios. Desse modo, o investimento é de natureza diferente para cada parte, mas é compartilhado, fazendo com que a região logre dos benefícios também.

Embora, na maioria dos casos, a qualificação tenha levado à empregabilidade, esta precisa ser questionada dentro da totalidade social, pois, apesar da ideia propagada de que a área de informática é promissora e existe um apagão de mão de obra qualificada, encontra-se profissionais habilitados desempregados ou completamente fora da área de formação. Estes casos, não por coincidência, estão localizados em cidades pequenas com baixo desenvolvimento industrial tecnológico. Conclui-se, portanto, que a análise da empregabilidade confrontada com formação profissional precisa, necessariamente, considerar fatores socioeconômicos, políticos e geográficos. Do ponto de vista de contribuição social para o desenvolvimento local e regional, em conjugada ação com as instituições de qualificação profissional, precisa haver a atuação pública correspondente para criação de mercados.

AGRADECIMENTOS: Ao IFG, pelo apoio ao desenvolvimento da pesquisa e pelo fomento à divulgação científica.

\section{REFERENCIAS}

ABSSTARTUP. O momento da startup brasileira e o futuro do ecossistema de inovação, São Paulo, SP: Absstartup e Accenture. 2018. Disponível em: https://abstartups.com.br/PDF/radiografia-startups-brasileiras.pdf. Acesso em: 18 jul. 2020.

ALKMIN, G. V.; HEIJMANS, R. D. Empregabilidade dos egressos tecnólogos do curso de Análise e Desenvolvimento de Sistemas nos institutos federais mineiros. In: WORKSHOP SOBRE EDUCAÇÃO EM COMPUTAÇÃO - WEI, 24., 2016, Porto Alegre. Anais [...]. Porto Alegre, RS: Sociedade Brasileira de Computação, 2016. p. 101-110. Disponível em: https://sol.sbc.org.br/index.php/wei/issue/view/508. Acesso em: 22 jun. 2020.

BRASIL. Ministério da Agricultura, Pecuária e Abastecimento. Levantamento sobre produção agrícola municipal. Brasília, DF: MAPA, 2019. 
BRUNO, L. Educação e desenvolvimento econômico no Brasil. Rev. Bras. Educ., Rio de Janeiro, v. 16, n. 48, p. 545-562, dez. 2011. DOI: https://doi.org/10.1590/S141324782011000300002

CARDOSO, P. P. Empregabilidade dos egressos: a educação profissional integrada ao ensino médio no extremo norte da Amazônia. Tese (Doutorado em Sociedade e Cultura da Amazônia) - Universidade Federal do Amazonas, Manaus, 2018.

CASTELLS, M. A sociedade em rede. 8. ed. São Paulo, SP: Paz e Terra, 2000. v. 1. Disponível em:

https://perguntasaopo.files.wordpress.com/2011/02/castells_1999 parte1_cap1.pdf. Acesso em: 18 ago. 2020.

CAZAROTTI, M. L. B.; BERNARDES, S. T. A. Cursos superiores de tecnologia: fundamentos, controvérsias \& desafios. Revista on line de Política e Gestão Educacional, Araraquara, v. 22, n. 3, p. 992-1046, set./dez. 2018. e-ISSN:1519-9029. DOI: https://doi.org/10.22633/rpge.v22i3.11368

COSTA, R. L.; LIBÂNEO, J. C. Educação profissional técnica a distância: A mediação docente e as possibilidades de formação. Educação em Revista, Belo Horizonte, n. 34, 2018. DOI: https://doi.org/10.1590/0102-4698180600

COSTA, R. L.; SOUZA, M. A. R.; THEREZA JÚNIOR, A. H. Materialismo históricodialético em pesquisas em informática na educação. In: JAQUES, P. A. et al. (Org.). Metodologia de pesquisa científica em informática na educação: abordagem quantitativa. Porto Alegre, RS: SBC, 2020. v. 2. (Série Metodologia de Pesquisa em Informática na Educação). Disponível em: https://metodologia.ceie-br.org/livro-3/. Acesso em: 14 ago. 2020.

DERMEVAL, D.; COELHO, J. A. P. M.; BITTENCOURT, I. I. mapeamento sistemático e revisão sistemática da literatura em informática na educação. In: JAQUES, P. A. et al. (Org.). Metodologia de pesquisa científica em informática na educação: abordagem quantitativa. Porto Alegre: SBC, 2020. v. 2. (Série Metodologia de Pesquisa em Informática na Educação). Disponível em: https://metodologia.ceie-br.org/livro-2. Acesso em: 14 ago. 2020.

FERNANDES, J. C. C. Educação tecnológica e empregabilidade: revelações de egressos. 2012. Tese (Doutorado) - Departamento de Educação, Pontifícia Universidade Católica de Goiás, Goiânia, 2012.

FRANÇA, I. S.; SOARES, B. Rede urbana regional: uma reflexão sobre as interações espaciais existentes entre a cidade média de Montes Claros e os centros emergentes de Pirapora, Janaúba e Januária no norte do estado de Minas Gerais, Brasil. In: ENCUENTRO DE GEÓGRAFOS DE AMÉRICA LATINA - EGAL, 13., 2011, Costa Rica. Anais [...]. Costa Rica: Universidad de Costa Rica, 2011. Disponível em: $\mathrm{http}$ ://observatoriogeograficoamericalatina.org.mx/egal13/Geografiasocioeconomica/Geografi aurbana/092.pdf. Acesso em: 15 ago. 2020.

GUIMARÃES, M. A. M.; SALLES, M. T. O acompanhamento de egressos como ferramenta de inserção no mercado de trabalho. In: CONGRESSO NACIONAL DE EXCELÊNCIA EM 
GESTÃO, 10., 2014, Rio de Janeiro. Anais [...]. Rio de Janeiro, RJ: Inovarse, 2014. Disponível em https://www.inovarse.org/node/2253. Acesso em: 24 ago. 2020.

HULLEY, S. B. et al. Delineando a pesquisa clínica-4. Porto Alegre, RS: Artmed, 2015.

IEGER, E. M. Da qualificação ao mercado de trabalho: um estudo de caso com egressos de um Curso Superior de Informática no Paraná. 2014. Dissertação (Mestrado) - Setor de Ciências Humanas, Universidade Federal do Paraná, Curitiba, 2014.

\section{JORNAL DO COMÉRCIO. Multinacional alemã Basf estuda implantar Centro}

Tecnológico em Porto Alegre. 20 nov. 2019. Disponível em:

https://www.jornaldocomercio.com/_conteudo/economia/2019/11/713059-multinacionalalema-basf-estuda-implantar-centro-tecnologico-em-porto-alegre.html. Acesso em: 23 ago. 2020 .

LUCIANO, A. P. C.; SANTOS, A. A. Caminhos do Licenciado em Computação no Brasil: Estudo de Mercado a Partir de uma Pesquisa com Egressos. In: CONGRESSO BRASILEIRO DE INFORMÁTICA NA EDUCAÇÃO (CBIE), 2.; SIMPÓSIO BRASILEIRO DE INFORMÁTICA NA EDUCAÇÃO (SBIE), 24., 2013, Campinas. Anais [...]. Campinas, SP: UNICAMP, 2013. Disponível em: https://www.brie.org/pub/index.php/sbie/article/view/2530. Acesso em: 23 ago. 2020.

MACHADO, A. S. Acompanhamento de egressos: caso CEFET/PR - Unidade Curitiba. 2001. 150 f. Dissertação (Mestrado em Engenharia de Produção) - Departamento de PósGraduação, Universidade Federal de Santa Catarina, Florianópolis, 2001.

MACHADO, L. R. S. Educação e divisão social do trabalho: contribuição para o estudo do ensino técnico industrial brasileiro. 2. ed. São Paulo, SP: Cortez, 1989.

MAZZUCATO, M. O estado empreendedor: desmascarando o mito do setor público x setor privado. São Paulo, SP: Portfolio-Penguin, 2014.

NUNES, P. S. Em busca do "tesouro": inserção profissional e inclusão digital nas trajetórias de egressos/integralizados de um curso de Técnico em Informática - PROEJA. 2011. Tese (Doutorado em Educação) - Universidade do Vale do Rio dos Sinos, São Leopoldo, 2011.

\section{PINHEIRO, L. J. M. Estudo com egressos da Licenciatura em Computação da}

Universidade de Brasília: as influências do curso na vida profissional e pessoal dos exalunos. 2017. 63 f. Monografia (Trabalho de Conclusão do Curso de Ciência da Computação) — Universidade de Brasília, Brasília, 2017.

PREFEITURA DE BAMBUÍ. Dados gerais do município de Bambuí. Página atualizada em 2020. Disponível em: https://www.bambui.mg.gov.br/dados-gerais. Acesso em: 28 ago. 2020.

ROSTIROLA, S. C. M.; OLIVEIRA, R. Programa de mapeamento de egressos relatório 2015-2016 do Instituto Federal Catarinense - Câmpus Videira. Videira, SC: Instituto Federal Catarinense / MEC, 2017. Disponível em: http://videira.ifc.edu.br/wpcontent/uploads/2015/11/relat\%C3\%B3rio-egressos.pdf. Acesso em: 23 ago. 2020. 
SANTOS, L. A capital da inovação: arranjos institucionais do empreendedorismo inovador no polo tecnológico de Florianópolis. Tese (Doutorado) - Centro de Filosofia e Ciências Humanas, Universidade Federal de Santa Catarina, Florianópolis, 2017.

SANTOS, L. B. Resenha de O Estado empreendedor: desmascarando o mito do setor público vs. setor privado. Publicações do Núcleo de Sociologia Econômica (NUSEC), 2015. Disponível em: https://nusec.paginas.ufsc.br/files/2015/04/Leandro-resenhaMAZZUCATO.pdf. Acesso em: 27 ago. 2020.

SANTOS, M. R. P. et al. Itinerários dos egressos do nível Médio Integrado, IFBA - Campus Jacobina. Ensino em Foco, v. 1, n. 2, 2018. Disponível em: https://publicacoes.ifba.edu.br/index.php/ensinoemfoco/article/view/486. Acesso em: 23 ago. 2020 .

SAVIANI, D. Trabalho e educação: fundamentos ontológicos e históricos. Revista Brasileira de Educação, v. 12 n. 34 jan./abr. 2007.

SOFTEX. Associação para promoção da excelência do software brasileiro. Overview do setor de tecnologia da informação brasileiro nos últimos dez anos. Campinas, 2019. Disponível em: https://softex.br/inteligencia/\#toggle-id-3. Acesso em 09 jun. 2020.

SOFTEX. Cadernos Temáticos do Observatório da Associação Para Promoção da Excelência do Software Brasileiro. Software e Serviços de TI. Campinas, 2012. Arquivo eletrônico https://www.softex.br/inteligencia/\#cadernostematicos. Acesso em 09 jun. 2020.

SOFTEX. Cadernos Temáticos do Observatório da Associação Para Promoção da Excelência do Software Brasileiro. Mercado de Trabalho e Formação de Mão De Obra em TI. Campinas, 2013. Disponível em: https://www.softex.br/inteligencia/\#cadernostematicos. Acesso em 09 jun. 2020.

VIEIRA, M. S. O. C.; GOMES, D. C.; SILVA, J. M. T. O papel do Instituto Federal de Educação, Ciência e Tecnologia (IFRN) para a qualificação e empregabilidade: um estudo dos egressos do curso de informática do IFRN em Currais Novos/RN. HOLOS, ano 27, v. 1, 2011. 


\section{Como referenciar este artigo}

COSTA, R. L. Mapeamento sistemático da literatura científica sobre egressos de cursos técnicos e superiores de informática e empregabilidade. Revista on line de Política e Gestão Educacional, Araraquara, v. 25, n. 3, p. 2670-2693, set./dez. 2021. e-ISSN:1519-9029. DOI: https://doi.org/10.22633/rpge.v25i3.14353

Submetido em: $14 / 08 / 2021$

Revisões requeridas em: 20/09/2021

Aprovado em: $15 / 11 / 2021$

Publicado em: 08/12/2021 